\title{
Birth of lambs of a pre-determined sex after in vitro production of embryos using frozen-thawed sex-sorted and re-frozen-thawed ram spermatozoa
}

\author{
F K Hollinshead, G Evans, K M Evans ${ }^{1}$, S L Catt ${ }^{2}$, W M C Maxwell and J K O’Brien \\ Centre for Advanced Technologies in Animal Genetics and Reproduction, Faculty of Veterinary Science, The \\ University of Sydney, NSW 2006, Australia, ${ }^{1}$ XY, Inc., Fort Collins, Colorado, USA and ${ }^{2}$ Sydney IVF, 4 O'Connell \\ Street, Sydney, NSW 2000, Australia
}

Correspondence should be addressed to J K O’Brien; Email: justineo@vetsci.usyd.edu.au

\begin{abstract}
The characteristics and functional capacity of ram spermatozoa frozen-thawed prior to and after flow cytometric sorting was assessed after incubation $\left(37^{\circ} \mathrm{C} ; 6 \mathrm{~h}\right)$, in vitro fertilisation (IVF), and transfer of fresh and vitrified in vitro produced embryos. Frozen-thawed spermatozoa from two rams were allocated to four treatment groups: (i) non-sorted (Control); (ii) sorted (FS); (iii) sorted then re-frozen (FSF) and (iv) re-frozen control (FCF). Frozen-thawed samples were separated into X- and Y-chromosome bearing spermatozoa using a high-speed sperm sorter after density gradient centrifugation (X: $88 \pm 1.5 \%$ and $\mathrm{Y}$ : $87 \pm 1.1 \%$ purity). After $6 \mathrm{~h}$ incubation $\left(37^{\circ} \mathrm{C}\right)$, the percentage of motile spermatozoa was higher $(P<0.001)$ for FS $(84 \pm 2.0 \%)$ compared with all other treatments (Control: $36 \pm 3.3 \%$, FSF: $28 \pm 3.1 \%$, FCF: $20 \pm 2.0 \%$ ). In a sperm migration test greater numbers of FS spermatozoa penetrated $5 \mathrm{~mm}$ into the artificial cervical mucus compared with spermatozoa from all other treatments $(152 \pm 39.4$ vs $31 \pm 9.2$ spermatozoa respectively; $P<0.05)$. Fertilisation and cleavage rates were higher $(P<0.05)$ for in vitro matured oocytes inseminated with Control compared with FSF spermatozoa. However, the Day 7 blastocyst development rate was higher for oocytes inseminated with FSF $(62.2 \%)$ than FS and Control spermatozoa (52.7 and 50.0\%; $P<\mathbf{0 . 0 5}$ ). The number of ewes pregnant (Day 60), lambing and the in vivo embryo survival rate was greater $(P<0.01)$ after the transfer of fresh embryos rather than vitrified embryos derived from $X-$ and Y-spermatozoa $(67.6,64.7$ and $\mathbf{4 1 . 2} \%$ vs $29.6,25.9$ and $\mathbf{1 4 . 8} \%$ respectively).Twenty-six of the $30(86.7 \%)$ lambs derived from sex-sorted spermatozoa were of the correct sex. These results demonstrate that frozen-thawed ram spermatozoa can be sex-sorted for immediate or future use after re-cryopreservation and, in conjunction with IVF and embryo transfer, can be used to efficiently produce offspring of pre-determined sex.

Reproduction (2004) 127 557-568
\end{abstract}

\section{Introduction}

The application of sex pre-determination using flow cytometric sorting of spermatozoa (Johnson et al. 1989) to the breeding of livestock and wildlife is limited when the sorter is located a long distance from the male(s) and/or female(s). High-purity sorting of frozen-thawed spermatozoa for immediate use (Hollinshead et al. 2002b, 2003, O'Brien et al. 2003) or re-cryopreservation for later use would enhance the commercial- and conservation-driven applications of the sexing technology.

The production of offspring using sex-sorted spermatozoa in conjunction with in vitro fertilisation (IVF) and embryo transfer (ET) has been reported in cattle (Cran et al. 1993, 1994, 1995, Fry et al. 2004), pigs (Rath et al. 1997, 1999, Abeydeera et al. 1998, Johnson et al. 2000), humans (Levinson et al. 1995, Fugger et al. 1998, Fugger
1999) and sheep (intra-cytoplasmic sperm injection; Catt et al. 1996). Improvements in sorting efficiency (Rens et al. 1998, 1999, Johnson \& Welch 1999) and cryopreservation methods (Schenk et al. 1999) for sex-sorted spermatozoa facilitated the production of offspring after low-dose artificial insemination (AI) in cattle (Seidel et al. 1999), sheep (Hollinshead et al. 2002a), horses (Lindsey et al. 2002) and elk (Schenk \& DeGrofft 2003).

The efficacy of sex-sorting frozen-thawed bull spermatozoa was previously investigated by Stap et al. (1998) and Lu et al. (1999). Poor resolution of the X- and Y-populations, low sorting rates and a low blastocyst development rate after IVF were reported (Lu et al. 1999). Improved preparation methods, involving the removal of the cryo-diluent from frozen-thawed samples before staining and sorting, have resulted in high resolution of $\mathrm{X}$ - and 
Y-populations and improved sorting rates (Hollinshead et al. 2002b, O'Brien et al. 2003). In the former studies, motility, acrosome integrity and migration through artificial cervical mucus were similar after sorting of frozenthawed compared with fresh ram spermatozoa.

The objectives of the present study were to (i) evaluate in vitro characteristics (motility, forward progressive motility (FPM), acrosome integrity and migration through an artificial cervical mucus) of frozen-thawed and sorted (FS) and frozen-thawed, sorted, and then re-frozen and thawed (FSF) ram spermatozoa after $6 \mathrm{~h}$ incubation at $37^{\circ} \mathrm{C}$; (ii) investigate the ability of FS and FSF spermatozoa to fertilise in vitro matured (IVM) oocytes and produce blastocysts; and (iii) produce offspring after the transfer of fresh and vitrified embryos derived from FS and FSF spermatozoa.

\section{Materials and Methods}

Procedures herein were approved by the University of Sydney's Animal Ethics Committee.

\section{Experimental design}

Ejaculates were collected from two Merino rams, housed at the University of Sydney, during the breeding season (January-May). Sorting parameters from each ejaculate were recorded (fresh treatment) and the ejaculates were frozen and thawed (Control treatment). One-third of the thawed control pellets was re-frozen and thawed (frozencontrol-frozen treatment (FCF)). Another third was flow cytometrically sorted and either assessed after sorting (FS) or re-frozen and thawed (FSF).

Thawed spermatozoa from Control, FCF, FS and FSF treatments were assessed for migration ability through artificial cervical mucus in a modified sperm migration test (SMT) after thawing $(0 \mathrm{~h})$ and for sperm characteristics after thawing $(0 \mathrm{~h})$ and incubation $\left(6 \mathrm{~h} ; 37^{\circ} \mathrm{C}\right)$. The latter involved assessment of acrosome status, motility and FPM. Control, FS and FSF spermatozoa were also co-incubated with IVM ovine oocytes for assessment of fertilisation, cleavage and blastocyst development. Each sperm evaluation was replicated three times.

\section{Semen collection and freezing}

Ejaculates were collected by artificial vagina from two Merino rams (Ram 1, Ram 2). Semen was diluted 1:4 (semen:diluent, $v / v$ ) using a zwitterion-buffered diluent containing $13.5 \%$ egg yolk and 6\% glycerol (ZWIT) (Molinia et al. 1996) and frozen and thawed using the pellet method described by Evans \& Maxwell (1987).

\section{Preparation of spermatozoa for sorting}

Thawed spermatozoa were prepared using multiple twostep Puresperm (Cook, Brisbane, QLD, Australia) gradients $(0.2 \mathrm{ml}$ thawed semen on $1 \mathrm{ml} 45 \%$ Puresperm on $1 \mathrm{ml}$ $90 \%$ Puresperm) centrifuged at $1000 \mathrm{~g}$ for $10 \mathrm{~min}$. Pellets containing motile spermatozoa were pooled after centrifugation and immediately diluted 1:4 (sperm pellet:diluent, v/v) with a modified Tris-buffered diluent (TRIS; $300 \mathrm{mM}$ tris-(hydroxymethyl) aminomethane, $27.8 \mathrm{mM}$ fructose, $94.7 \mathrm{mM}$ citric acid, $87.9 \mathrm{IU} / \mathrm{ml}$ penicillin-G, $35.3 \mathrm{IU} / \mathrm{ml}$ streptomycin sulphate and $0.3 \% \mathrm{w} / \mathrm{v}$ BSA) and centrifuged again at $600 \mathrm{~g}$ for $5 \mathrm{~min}$. Both the neat fresh semen and the thawed prepared sperm pellets were diluted to $400 \times 10^{6}$ spermatozoa/ml with TRIS containing 267$311 \mu \mathrm{M}$ Hoechst stain (H33342; Sigma, St Louis, MO, USA). These stain concentrations had been previously optimised for each ram (data not shown). The samples were incubated at $34{ }^{\circ} \mathrm{C}$ and rotated every $15 \mathrm{~min}$ to improve staining uniformity. After $1 \mathrm{~h}$ incubation the stained samples were extended 1:1 (sperm sample:diluent, $\mathrm{v} / \mathrm{v})$ with TRIS $\left(34^{\circ} \mathrm{C}\right)$ containing $4 \%(\mathrm{v} / \mathrm{v})$ egg yolk and $0.002 \%(\mathrm{w} / \mathrm{v})$ food dye (Warner Jenkinson Company, Inc., St Louis, MO, USA) and were then filtered (37 $\mu \mathrm{m}$, Falcon 2235; Becton Dickinson, Franklin Lakes, NJ, USA).

\section{Flow cytometric sorting}

$\mathrm{X}$ - and Y-chromosome bearing spermatozoa were separated using a high speed cell sorter (MoFlo SX; DakoCytomation, Fort Collins, CO, USA) modified for sperm sorting (Johnson \& Pinkel 1986, Rens et al. 1998, 1999, Johnson \& Welch 1999) operating at 40 psi with a TRIS sheath fluid and running at $200 \mathrm{~mW}$ with an argon laser. Two types of sorting were used. For in vitro fertilisation (IVF) samples, gates were placed around the viable and correctly oriented population during sorting to obtain purities greater than $85 \%$ for $\mathrm{X}$ - and $\mathrm{Y}$-chromosome bearing sperm populations. Spermatozoa required for all other sperm quality tests were processed through the sperm sorter but with the gates set during sorting to include the entire viable (oriented and non-oriented) sperm population. The average sorting rate of spermatozoa for the sperm quality assessments was 8000-10000 spermatozoa per second depending on the number of viable cells available for sorting. Average flow rates for both sorting conditions were 18000-22 000 events per second. All spermatozoa were sorted into $10 \mathrm{ml}$ centrifuge tubes containing $0.25 \mathrm{ml}$ Androhep (AH) (Minitüb, GmbH, Landshut, Germany) supplemented with $20 \%$ egg yolk (v/v) adjusted to $\mathrm{pH} 7.4$. Five million spermatozoa were collected for each treatment in approximately $5 \mathrm{ml}$ TRIS sheath fluid (final concentration of egg yolk $2 \%, \mathrm{v} / \mathrm{v}$ ).

\section{Reanalysis of sorted spermatozoa}

At the completion of sorting of each sample, $500000 \mathrm{X}$ and Y-chromosome bearing fresh or frozen-thawed spermatozoa were collected and processed as described by Welch \& Johnson (1999), to estimate the X- and Y-purity and to predict the proportion of male and female offspring. The proportion of correctly oriented spermatozoa, percentage of non-viable spermatozoa, sort rate, R-value 
(histogram measurement of the separation between the Xand Y-sperm populations) and purity were recorded for every fresh and frozen-thawed sample prepared.

\section{Preparation of spermatozoa for post-sort and post- thaw assessments}

Sorted spermatozoa (FS) were centrifuged at $700 \mathrm{~g}$ for $6 \mathrm{~min}$ at room temperature $\left(21^{\circ} \mathrm{C}\right)$. Each $50 \mu \mathrm{l}$ pellet was slowly re-suspended 1:4 (sperm pellet:diluent, $v / v$ ) with either ZWIT diluent and re-frozen (FSF treatment) or Sydney IVF sperm buffer (Sperm buffer; Cook) and re-centrifuged in $2 \mathrm{ml}$ centrifuge tubes (ThermoTrace Ltd, Noble Park, VIC, Australia) at $500 \mathrm{~g}$ for $3 \mathrm{~min}$ in preparation for IVF (FS treatment). Spermatozoa sorted but not sexed were resuspended 1:8 $(50 \mu$ l pellet:diluent, $v / v)$ with $\mathrm{AH}$ containing $20 \%(\mathrm{v} / \mathrm{v})$ egg yolk in preparation for incubation $\left(37^{\circ} \mathrm{C} ; 6 \mathrm{~h}\right)$ and sperm quality evaluation. In preparation for IVF, a thawed pellet of Control spermatozoa was carefully placed under $0.5 \mathrm{ml}$ of sperm buffer (Cook) and incubated for $1 \mathrm{~h}$ at $37^{\circ} \mathrm{C}$ (Brown \& Radziewic 1998). The upper $100 \mu \mathrm{l}$ containing motile spermatozoa were removed and the concentration of spermatozoa determined by haemocytometer. For incubation and sperm quality assessment, an aliquot containing $5 \times 10^{6}$ thawed control spermatozoa was removed prior to preparation for sorting and was either (i) extended to $0.25 \mathrm{ml}$ with $\mathrm{AH}$ containing $20 \%(\mathrm{v} / \mathrm{v})$ egg yolk (Control treatment) or (ii) re-frozen in $0.25 \mathrm{ml}$ of ZWIT diluent (FCF treatment). FCF and FSF spermatozoa were thawed at $37^{\circ} \mathrm{C}$ by agitation in $10 \mathrm{ml}$ dry glass test tube and prepared for incubation $\left(37^{\circ} \mathrm{C}, 6 \mathrm{~h}\right)$ or co-incubation with IVM oocytes using the same methods as for the FS spermatozoa.

\section{SMT}

Spermatozoa from each treatment were assessed at $0 \mathrm{~h}$ after thawing (Control, FSF and FCF) or sorting (FS) for their ability to migrate through an artificial cervical mucus $(10 \mathrm{mg} / \mathrm{ml}$ sodium hyaluronate diluted with $25 \% \mathrm{AH}$ containing $1 \% \mathrm{w} / \mathrm{v}$ BSA; Bioniche, Armidale, NSW, Australia) by an SMT developed for human spermatozoa (Mortimer et al. 1990) and further modified for low numbers of sorted ram spermatozoa (Hollinshead et al. 2002b, $\mathrm{O}^{\prime}$ Brien et al. 2003). Aliquots $(50 \mu \mathrm{l})$ containing $1 \times 10^{6}$ spermatozoa from each treatment were incubated $\left(37^{\circ} \mathrm{C}\right.$; $1 \mathrm{~h}$ ) in BEEM capsules (BEEM standard embedding capsules; ProSciTech, Thuringawa, QLD, Australia) containing a vertically placed $0.3 \times 0.3 \times 100 \mathrm{~mm}$ rectangular capillary tube (Microslides; VitroCom, Mountain Lakes, NJ, USA) filled with artificial cervical mucus. Evaluations of the number of spermatozoa from each treatment migrating $5 \mathrm{~mm}$ into artificial mucus and the distance travelled by the vanguard spermatozoon from each treatment after $1 \mathrm{~h}$ incubation $\left(37^{\circ} \mathrm{C}\right)$ were evaluated using phase contrast microscopy ( $\times 200)$ (Olympus, Tokyo, Japan).

\section{Motility and acrosome integrity}

The remainder of each sperm sample was incubated at $37^{\circ} \mathrm{C}$ for $6 \mathrm{~h}$. Assessments of percentage motile spermatozoa (to the nearest 5\%) and FPM rating (FPM: $0-5$ scale; $0=$ no movement, $5=$ rapid forward progression; modified from Howard et al. 1986) were made by examining several different fields by phase contrast microscopy $(\times 100$, Olympus) after thawing (Control, FCF and FSF) or sorting (FS) and 3 and $6 \mathrm{~h}$ incubation. Dry smears were made after thawing or sorting and $3 \mathrm{~h}$ incubation for the assessment of acrosome integrity by fluorescent isothiocyanate-conjugated peanut agglutinin staining as described by Roth et al. (1998). A total of 200 spermatozoa per treatment were examined by phase contrast microscopy ( $\times 200$, Olympus) and were considered acrosome intact if the acrosome stained bright green and acrosome reacted if there was no staining or only a single band of green fluorescence at the equatorial segment.

\section{IVM, IVF and culture of oocytes}

Methods of in vitro production of embryos in the present study have been described previously $\left(\mathrm{O}^{\prime} \mathrm{Brien}\right.$ et al. 1996). Briefly, ovaries were collected from 407 mature Merino ewes at two local abattoirs during the period December 2002 to January 2003. Oocytes were aspirated from follicles $2-4 \mathrm{~mm}$ in diameter and only those with a homogeneous ooplasm surrounded by several layers of cumulus cells were selected for IVM $(n=1047)$. Groups of 25-35 cumulus-oocyte complexes were incubated in multi-well dishes (Nunclon; Inter Med, Roskilde, Denmark) containing $450 \mu \mathrm{l}$ maturation medium overlaid with $400 \mu \mathrm{l}$ mineral oil (M 8410; Sigma) for $22 \mathrm{~h}$. All stages of in vitro culture took place at $38.5^{\circ} \mathrm{C}$ in a humidified atmosphere of $5 \% \mathrm{O}_{2}: 6 \% \mathrm{CO}_{2}: 89 \% \mathrm{~N}_{2}$ (V-MINC-1000; Cook). The maturation medium contained Medium 199 (Gibco BRL, Grand island, NY, USA) with Earle's salts, $15 \mathrm{mM}$ L-glutamine, $25 \mathrm{mM}$ sodium bicarbonate, $25 \mathrm{mM}$ Hepes supplemented with $20 \%(\mathrm{v} / \mathrm{v})$ sheep serum (ThermoTrace), $10 \mu \mathrm{g} / \mathrm{ml}$ follicle-stimulating hormone (Folltropin-V; Bioniche), $10 \mu \mathrm{g} / \mathrm{ml}$ luteinising hormone (Lutropin-V; Bioniche), $124 \mathrm{lU} / \mathrm{ml}$ penicillin and $37 \mathrm{IU} / \mathrm{ml}$ streptomycin.

Following IVM, 25-30 oocytes were co-incubated with $1 \times 10^{6}$ motile spermatozoa $/ \mathrm{ml}$ from each treatment (Control, FS and FSF X- and Y-chromosome bearing spermatozoa; $n=5$ treatment groups/ram) for $3 \mathrm{~h}$ in multi-well dishes (Nunclon) containing $400 \mu \mathrm{l}$ fertilisation medium overlaid with $400 \mu \mathrm{l}$ oil. The fertilisation medium comprised bicarbonate-buffered synthetic oviduct fluid medium (Tervit et al. 1972) supplemented with $2 \%(\mathrm{v} / \mathrm{v})$ heat-inactivated and filtered sheep serum (ThermoTrace). Presumptive zygotes were then transferred to $10 \mu \mathrm{l}$ droplets of Sydney IVF (SIVF) cleavage medium (Cook) overlaid with oil and cultured for 4 days. After this time, cleaved oocytes were transferred to $10 \mu \mathrm{l}$ droplets of Sydney IVF (SIVF) blastocyst medium (Cook) overlaid with oil for 3 days. The protein source used in both the SIVF cleavage 
and blastocyst media was $200 \mathrm{mg} / \mathrm{ml}$ human serum albumin (HSA) (CAF-BCF; Scandinavian IVF Science, Goteborg, Sweden). For quality control, parthenogenic development was assessed by evaluating cleavage and blastocyst development of IVM oocytes incubated without spermatozoa (three replicates, $n=69$ ).

\section{Oocyte and embryo assessment}

Oocytes were visually assessed for cleavage at 24 and $48 \mathrm{~h}$ after insemination ( $\times 100$, Olympus). At $48 \mathrm{~h}$ post-insemination (p.i.) uncleaved oocytes were fixed in ethanol:acetic acid:chloroform $(6: 3: 1)$ for $24 \mathrm{~h}$, stained with $1 \%$ orcein $(\mathrm{w} / \mathrm{v})$ and examined using phase contrast microscopy ( $\times 200$, Olympus) to identify those undergoing penetration and monospermic or polyspermic fertilisation. The maturation rate was calculated at $48 \mathrm{~h}$ p.i as the proportion of total oocytes undergoing cleavage and the number of uncleaved oocytes containing two pronuclei. The number of oocytes developing to the blastocyst stage was assessed ( $\times 100$, Olympus) on Days 5, 6 and 7 p.i.. The criteria for blastocyst formation were the presence of a partially or fully formed blastocoele and a distinguishable inner cell mass and trophoblast population. Blastocysts were further categorised into five developmental stages based on their degree of expansion and hatching (O'Brien et al. 1997): early blastocyst (blastocoele beginning to form); blastocyst (blastocoele formed); expanded blastocyst (ExB: large increase in blastocyst diameter and thinning of the zona pellucida); hatching blastocyst $(\mathrm{HgB})$; and hatched blastocyst $(\mathrm{HB})$. Blastocysts at the blastocyst, ExB, $\mathrm{HgB}$ and $\mathrm{HB}$ stages were graded into three groups based on the development of the inner cell mass and trophectoderm (Gardner \& Schoolcraft 1999).

\section{Embryo vitrification and re-warming}

Day 6 and 7 blastocysts were cryopreserved using the open-pulled straw vitrification method (Vajta et al. 1998). Briefly, embryos were first washed in a Hepes-buffered M91 medium (Sydney IVF cryobuffer; Cook) supplemented with $6 \%(\mathrm{v} / \mathrm{v})$ HSA. This cryobuffer medium was used as the basic holding medium for both vitrification and thawing. All media were warmed to $38.5^{\circ} \mathrm{C}$ and all manipulations were carried out on a heated stage $\left(38.5^{\circ} \mathrm{C}\right)$ in a warm room $\left(26-28^{\circ} \mathrm{C}\right)$. The blastocysts were then exposed to cryobuffer medium containing $7.5 \%(\mathrm{v} / \mathrm{v})$ ethylene glycol (EG) (E 9129; Sigma) and 7.5\% (v/v) dimethyl sulphoxide (DMSO) (D2650; Sigma) for $3 \mathrm{~min}$. Blastocysts were then transferred to and mixed with cryobuffer medium containing $1 \mathrm{M}$ sucrose, $16.5 \%$ EG and $16.5 \%$ DMSO, and loaded by capillary action into openpulled straws before plunging into liquid nitrogen all within $25 \mathrm{~s}$. Day 6 blastocysts and early ExBs were rewarmed the day before transfer and Day 6 (ExB and $\mathrm{HgB}$ ) and all Day 7 blastocysts were re-warmed on the morning they were to be transferred. All blastocysts were warmed by holding each straw for $3 \mathrm{~s}$ in air and then immersing the end containing the blastocysts in $1 \mathrm{ml}$ cryobuffer medium containing $0.33 \mathrm{M}$ sucrose $\left(38.5^{\circ} \mathrm{C}\right)$. After $5 \mathrm{~min}$, blastocysts were transferred to cryobuffer medium containing $0.16 \mathrm{M}$ sucrose and held for $5 \mathrm{~min}$, and finally they were moved into cryobuffer medium for a further $5 \mathrm{~min}$. Day 6 blastocysts (blastocysts and early ExBs) were subsequently cultured in SIVF blastocyst medium for $18 \mathrm{~h}$ prior to transport. Late Day 6 and Day 7 blastocysts were placed immediately into transport medium (see below) and transferred into recipients within $4 \mathrm{~h}$ of re-warming. Only early Day 6 embryos were assessed for re-expansion of the blastocoele prior to transfer, since late Day 6 and Day 7 embryos were not cultured after re-warming.

\section{ET}

Fresh blastocysts forming on Day 6 of culture were transferred into 34 mature Border Leicester $\times$ Merino $(B L M)$ crossbred ewes early in the breeding season (February 2003). The transfers were performed at a commercial sheep farm located in the southern highlands of NSW (ET Trial 1). Blastocysts forming on Day 6 and Day 7 of culture were vitrified and later re-warmed and transferred into 27 mature Merino ewes in April 2003 at The University of Sydney farm, Camden, NSW (ET Trial 2).

Fresh Day 6 embryos were transported and held in Sydney IVF buffer and $2.5 \%(\mathrm{v} / \mathrm{v}) \mathrm{HSA}$ at $38.5^{\circ} \mathrm{C}$ until transfer (2.5-4h). Re-warmed Day 6 and Day 7 embryos were transported in Sydney IVF buffer and 5\% (v/v) HSA and held at $38.5^{\circ} \mathrm{C}$ until transfer $(1.5-3 \mathrm{~h})$. Both fresh and vitrified embryos were graded using light microscopy ( $\times 100$, Olympus) immediately prior to transfer. Sixtyeight grade 1 blastocysts at the blastocyst-ExB, ExB and $\mathrm{HgB}$ developmental stages produced on Day 6 of culture were transferred into 34 synchronised recipients (ET Trial $1)$. Twenty grade 1 blastocysts at the blastocyst or ExB stage and 34 grade 1 ExBs and $\mathrm{HgBs}$ produced on Day 6 and Day 7 of culture, respectively, were vitrified and later re-warmed and transferred into 27 synchronised recipient ewes (ET Trial 2).

Oestrus was synchronised in 50 mature BLM crossbred ewes (ET Trial 1; 3 years old, 65-70 kg) and 30 mature Merino ewes (ET Trial 2; 5 years old, 45-50 kg) with progestagen-impregnated intravaginal sponges containing $40 \mathrm{mg}$ fluogestone acetate $(40 \mathrm{mg}$ Chronogest; Intervet, Bendigo, VIC, Australia). The sponges were removed after 13 days and the ewes were injected i.m. with $500 \mathrm{IU}$ (ET Trial 1) or $400 \mathrm{IU}$ (ET Trial 2) pregnant mare serum gonadotrophin (Pregnecol; Bioniche).

ET was performed using a modified laparoscopic minilaparotomy technique (O'Brien et al. 1996) either 6 days (ET Trial 1) or 7 days (ET Trial 2) after the onset of oestrus. Recipient ewes were treated 20 min before surgery with a combination of i.m. sedatives ( $1 \mathrm{ml}$ Ketamil; Ilium, Troy Laboratories, Smithfield, NSW, Australia); $2 \mathrm{ml}$ diazepam 
(Pamlin; Parnell Laboratories, Alexandria, NSW, Australia); and $1 \mathrm{ml}$ buprenorphine hydrochloride (Temgesic; Reckitt Benckiser, Auckland, New Zealand) and local anaesthetic (4 ml Lignocaine; Ilium, Troy Laboratories). Before transfer, both the ovaries were visualised by manipulation with a probe to check for the presence of copora lutea. Ewes which had failed to ovulate were excluded from the study ( $n=16$ in ET Trial $1 ; n=3$ in ET Trial 2). The tip of the uterine horn ipsilateral to an ovary with at least one corpus luteum was exteriorised through a $1-2 \mathrm{~cm}$ midventral incision. A small opening was made in the tip of the uterine horn and two blastocysts of the same developmental stage (blastocyst, ExB, HgB, HB), age (Day 6 or 7), grade (1 or 2) and from the same sperm treatment (Control, FS and FSF $X$ or $Y$ ) and embryo treatment (fresh, vitrified, thawed and incubated or vitrified and thawed) were transferred into each recipient using a $10 \mu \mathrm{l}$ capillary pipette (Unopette; Becton Dickinson). After ET each ewe was given a non-steroidal anti-inflammatory i.m. injection (1 ml Ketoprofen; Nature Vet, Agnes Banks, NSW, Australia).

During transfer of the fresh embryos (ET Trial 1) a poor ovulatory response was noted in $88 \%$ (30/34) of recipients. Progesterone sponges were placed in each of the recipient ewes from Day 12 to Day 20 of gestation to help maintain pregnancy (Pearce et al. 1984, Scaramuzzi et al. 1988).

\section{Pregnancy diagnosis}

Jugular blood samples were collected from each recipient ewe on Day 20 after oocyte insemination and plasma progesterone concentrations were determined with a commercially available RIA (Spectra; Orion Diagnostics, Helinski, Finland). Ewes with progesterone concentrations greater than $1.2 \mathrm{ng} / \mathrm{ml}$ were considered pregnant (Robertson \& Sarda 1971). At Day 60 of gestation all recipient ewes were scanned by ultrasound for detection of foetuses. Pregnancy loss in ewes was calculated as: (Number of ewes pregnant at Day 20 minus Number of ewes pregnant at Day 60)/(Number of ewes pregnant at Day 20). Foetal loss was determined as: (Number of ewes pregnant at Day 60 minus Number of ewes lambing)/(Number of ewes pregnant at Day 60).

\section{Lambing}

At the start of the third trimester of gestation, pregnant ewes were separated from the flock and placed in sheltered paddocks and provided with supplementary feed in the form of lupin grains. Several days before the commencement of lambing, ewes were placed in small sheltered paddocks and observed $24 \mathrm{~h}$ a day until the end of lambing. Lambs were weighed, measured (crown-rump length and head width), identified for sex and ear-tagged within $6 \mathrm{~h}$ of birth. In vitro embryo survival rate was calculated as: ((Number of lambs born)/(Number of embryos transferred)) $\times 100$.
Due to the large size of a proportion of the lambs and associated birthing difficulties and ewe and lamb mortality experienced during the lambing of recipient crossbred ewes in ET Trial 1, a combination of $5 \mathrm{ml}$ dexame thasone (Dexadreson $2 \mathrm{mg} / \mathrm{ml}$; Intervet) and $5 \mathrm{ml}$ oestradiol benzoate (Mesalin $0.2 \mathrm{mg} / \mathrm{ml}$; Intervet) was given at Day 143 of gestation to each of the Merino recipient ewes in ET Trial 2 to induce earlier births and smaller offspring (Ptak et al. 2002).

\section{Statistical analysis}

Statistical analyses were performed using GENSTAT computer program (Version 4.2; Numerical Algorithms Group (NAG) Ltd, Oxford, UK). Data for sorting, motility, FPM rating and the mean distance travelled by the vanguard spermatozoon were analysed by ANOVA. Motility and FPM rating measurements at 0,3 and $6 \mathrm{~h}$ incubation were subjected to natural log transformation and analysed by repeated-measures ANOVA. The number of spermatozoa migrating $5 \mathrm{~mm}$ into the artificial cervical mucus was analysed by log-linear regression and the acrosomal status of spermatozoa from each treatment was determined by binomial logistic regression. Statistical differences in the proportion of oocytes undergoing fertilisation and cleaved oocytes developing to the blastocyst stage and the proportion of grade 1 embryos developing on Day 6 or Day 7 were analysed by binomial logistic regression. The pregnancy and lambing rate, and pregnancy and foetal loss after the transfer of fresh and vitrified embryos into recipient ewes were also analysed by binomial logistic regression. Lamb weight, body length, head width and gestation length were analysed by ANOVA. Proportional data for the sex ratio of offspring and in vivo embryo survival were analysed by Chi-square analysis and Fisher's exact test using the SigmaStat computer program (Version 2.0; SPSS, Inc., San Rafael, CA, USA).

\section{Results}

\section{Sorting efficiency}

High resolution of $\mathrm{X}$ - and $\mathrm{Y}$-sperm populations was achieved for both fresh and frozen-thawed samples (Fig. 1). Re-analysis revealed high levels of purity for $X$ and Y-sorted samples obtained from fresh (X: $89 \pm 2.0 \%$, $\mathrm{Y}: 88 \pm 1.2 \%)$ and frozen-thawed (X: $89 \pm 1.0 \%$, Y: $89 \pm 1.3 \%$ ) spermatozoa. There was a greater proportion of non-viable sperm (Fig. 1a and b) for frozen-thawed (FS and FSF treatment) compared with fresh samples $(25 \pm 1.7$ and $12 \pm 1.6 \%$ respectively; $P<0.001)$. The percentage of oriented spermatozoa (Fig. 1a and b) was higher for fresh $(60 \pm 3.0 \%)$ than frozen-thawed samples $(47 \pm 1.5 \%$; $P<0.001)$. Fresh spermatozoa were sorted at higher rates than frozen-thawed spermatozoa $(3540 \pm 239.0$ vs $1783 \pm 151.0$ spermatozoa per second respectively; $P<0.001)$. There was no ram effect on any of the sorting parameters. 

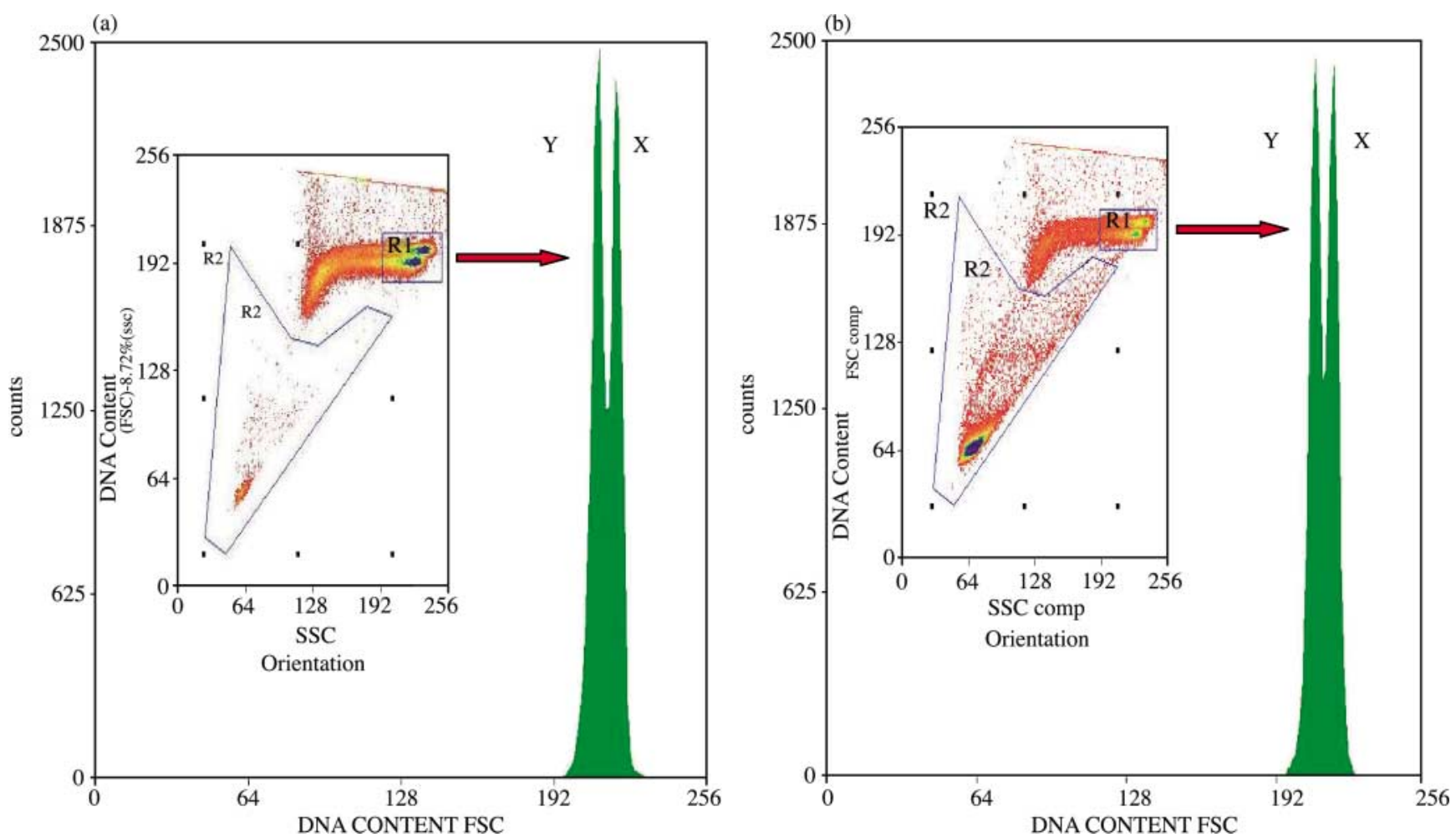

Figure 1 Flow cytometric histograms and dot plots derived from fresh (a) and frozen-thawed (b) spermatozoa from the same ejaculate. The arrows indicate that the information from the spermatozoa gated in R1 is then illustrated as a bivariate histogram. R1 (region 1) represents the correctly orientated sperm population; R2 (region 2) represents non-viable spermatozoa.

\section{SMT}

More sorted frozen-thawed spermatozoa derived from frozen-thawed samples (FS) penetrated $5 \mathrm{~mm}$ into the artificial cervical mucus compared with Control, FCF and FSF spermatozoa $(P<0.01)$ and more Control spermatozoa migrated $5 \mathrm{~mm}$ in the capillary tube than spermatozoa that had been frozen and thawed twice (FCF; Table 1; $P<0.01$ ). Higher numbers of spermatozoa reached $5 \mathrm{~mm}$ for Ram 1 than Ram $2(82 \pm 26.7$ vs $40 \pm 9.0 ; P<0.01)$. The mean distance travelled by the vanguard spermatozoon was similar for all treatments.

Table 1 Mean ( \pm S.E.M.) number of spermatozoa migrating $5 \mathrm{~mm}$ into the artificial cervical mucus and the mean ( \pm S.E.M.) distance travelled by the vanguard spermatozoon from the frozen-thawed non-sorted (Control), frozen-thawed and sorted (FS), frozen-thawed and re-frozen and thawed (FCF), and frozen-thawed, sorted and re-frozen and thawed (FSF) treatment after $1 \mathrm{~h}$ incubation $\left(37^{\circ} \mathrm{C}\right)$.

\begin{tabular}{lcc}
\hline Treatment & $\begin{array}{c}\text { No. of spermatozoa } \\
\text { reaching } \mathbf{5} \mathbf{~ m m}\end{array}$ & $\begin{array}{c}\text { Vanguard distance } \\
(\mathbf{m m})\end{array}$ \\
\hline Control & $56 \pm 16.4^{\mathrm{b}}$ & $33 \pm 0.2$ \\
FCF & $7 \pm 1.3^{\mathrm{c}}$ & $27 \pm 0.4$ \\
FS & $152 \pm 3.9^{\mathrm{a}}$ & $25 \pm 0.3$ \\
FSF & $31 \pm 9.8^{\mathrm{bc}}$ & $29 \pm 0.4$ \\
\hline
\end{tabular}

${ }^{\mathrm{abc}}$ Within columns, values with different superscripts differ $(P<0.01)$

\section{Assessment of motility, FPM and acrosome integrity}

After thawing, FS spermatozoa had higher motility than spermatozoa from all other treatments $(P<0.001)$. Control and FSF treatments had a similar proportion of motile spermatozoa, which was higher than FCF over the $6 \mathrm{~h}$ incubation period (Fig. 2a; $P<0.001$ ). After $3 \mathrm{~h}$ of incubation, motility of spermatozoa declined $(P<0.001)$ for all treatments except for FS, which maintained similar motility over the $6 \mathrm{~h}$ incubation period (Fig. 2a).

The FPM rating of spermatozoa was higher $(P<0.001)$ for the Control than for all other treatments (FS, FSF and FCF; Fig. 2b). After $6 \mathrm{~h}$ incubation, FS spermatozoa had a higher FPM rating than spermatozoa that had been re-frozen (FCF and FSF; Fig. 2b; $P<0.001$ ). At $0 \mathrm{~h}$ post-thaw, FPM was higher for Control and FCF spermatozoa compared with FS and FSF spermatozoa $(P<0.001)$. The FPM rating of FS, FSF and FCF spermatozoa increased after $1 \mathrm{~h}$ incubation $(P<0.001)$ but then gradually declined (Fig. $2 \mathrm{~b} ; P<0.001)$. Similar to motility, FPM of FS spermatozoa was maintained throughout the incubation period (Fig. 2b).

Spermatozoa that were re-frozen and thawed (FSF and FCF) had fewer intact acrosomes after the $6 \mathrm{~h}$ incuba tion period than Control and FS spermatozoa $(86 \pm 2.6$ and $83 \pm 1.6 \%$ vs $92 \pm 1.4$ and $90 \pm 1.3 \%$ respectively; $P<0.05)$. 
(a)

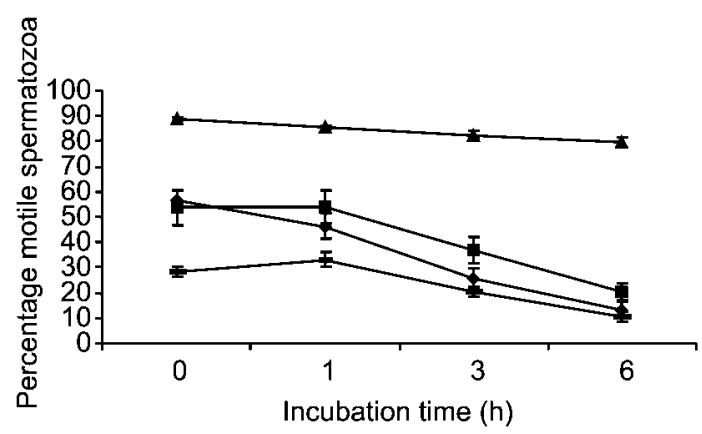

(b)

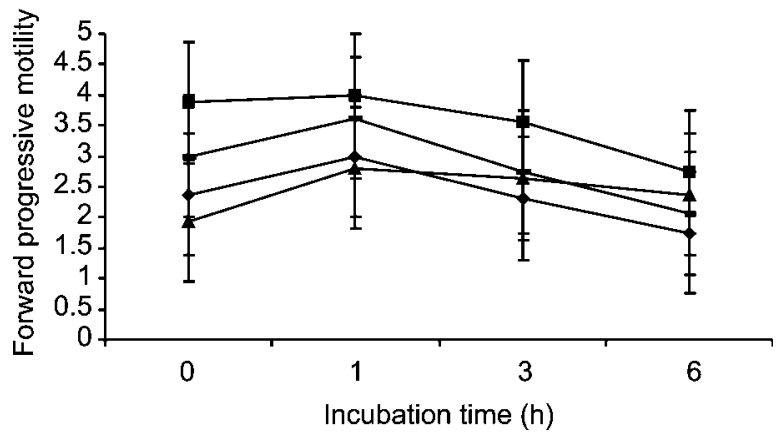

Figure 2 Motility (a) and FPM (b) of FS ( $\mathbf{\Delta})$ and non-sorted Control $\mathbf{\square})$ and FSF ( $)$ and FCF $(\boldsymbol{-})$ spermatozoa after thawing $(0 \mathrm{~h})$ and incubation for $6 \mathrm{~h}$ at $37^{\circ} \mathrm{C}$. Values are means \pm S.E.M.

\section{Effect of sperm preparation for IVF on motility, FPM and acrosome integrity}

The proportion of motile spermatozoa was higher for frozen-thawed spermatozoa after sorting (FS; $85 \pm 1.5 \%$ ) and thawing (FSF; $71 \pm 5.0 \%$ ) than for non-sorted frozen-thawed spermatozoa (Control; $45 \pm 4.5 \%$; Fig. $3 \mathrm{a}$; $P<0.001$ ). However, after preparation for IVF, involving a swim-up for Control spermatozoa, and wash and centrifugation for sorted (FS and FSF) spermatozoa, the percentage of motile Control spermatozoa significantly increased $(75 \pm 6.1 \% ; P<0.001)$ but decreased for the FS and FSF treatments $(60 \pm 8.3$ and $32 \pm 4.6 \%$ respectively; Fig. 3a). FS spermatozoa maintained a higher motility after IVF preparation than FSF spermatozoa $(P<0.001)$.

Spermatozoa from all treatments had higher FPM before than after the preparation for IVF (Fig. 3b; $P<0.05$ ). Overall, Control spermatozoa had a higher FPM rating than sorted spermatozoa (FS and FSF; Fig. 3b; $P<0.05$ ).

Spermatozoa from each treatment had a similar percentage of intact acrosomes both before and after preparation for IVF (results not shown).

\section{IVF and early embryo development}

The overall oocyte maturation rate was 90.6\% (949/1047). The proportions of oocytes fertilised and of zygotes that had cleaved $48 \mathrm{~h}$ after insemination were higher after (a)

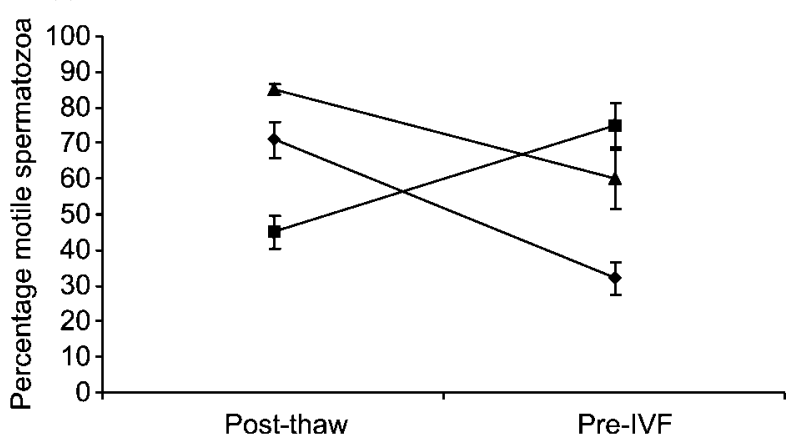

(b)

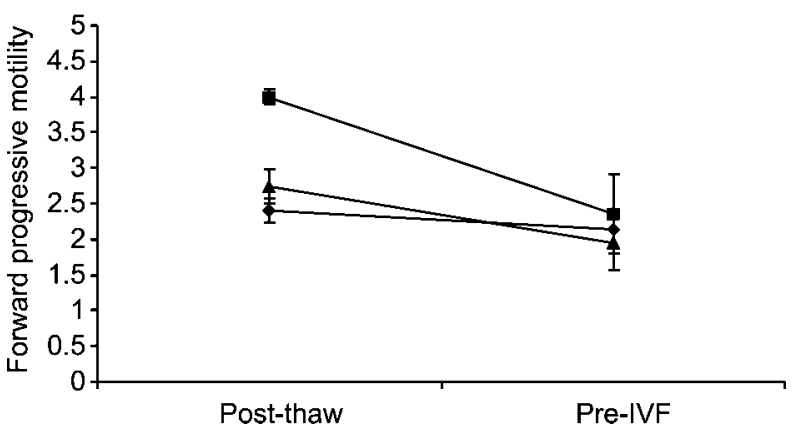

Figure 3 Motility (a) and FPM (b) of FS ( $\mathbf{\Delta})$ and non-sorted Control $(\boldsymbol{\square})$ and FSF $(\bullet)$ spermatozoa after thawing (Post-thaw) and preparation for IVF (Pre-IVF). Values are means \pm S.E.M.

insemination with Control than FSF spermatozoa (Table 2; $P<0.05)$. However, the proportion of cleaved oocytes that developed to blastocysts by Day 7 was significantly higher after co-incubation with FSF than with Control or FS spermatozoa $(P<0.05$; Table 2$)$. A similar proportion of blastocysts developed on Day 5 and Day 6 of culture after insemination with FS, FSF or Control spermatozoa (Table 2). There was no effect of ram (Ram 1, Ram 2) or sex (X- or Y-chromosome bearing spermatozoa) on fertilisation, cleavage or blastocyst development. Cleavage of oocytes in a parthenogenic control group (3/69; 4.3\%) and polyspermic fertilisation $(20 / 949 ; 2.1 \%)$ were low.

\section{Embryo quality}

Overall, embryo quality was high (grade 1: 70.7\%; 215/304) with no difference in the proportion of grade 1 blastocysts developing from oocytes inseminated with Control, FS or FSF spermatozoa. For all treatments, a higher proportion of grade 1 embryos developed on Day 6 (88.3\%; 159/180) than Day 7 (52/125; 41.6\%; $P<0.05)$. All Day 6 vitrified embryos underwent re-expansion during the $18 \mathrm{~h}$ culture after re-warming.

\section{Pregnancy rate and pregnancy loss}

Data for the number of recipient ewes pregnant as determined by progesterone assay on Day 20 and by ultrasound on Day 60 are presented in Table 3. A higher 
Table 2 Fertilisation and early embryonic development of oocytes after incubation with frozen-thawed non-sorted (Control), frozen-thawed and sorted (FS) and frozen-thawed, sorted then frozen-thawed (FSF) ram spermatozoa.

\begin{tabular}{|c|c|c|c|c|c|c|}
\hline \multirow[b]{2}{*}{ Treatment } & \multirow[b]{2}{*}{ No. matured oocytes* fertilised ${ }^{1}(\%)$} & \multicolumn{2}{|c|}{$\begin{array}{c}\text { No. mature oocytes } \\
\text { undergoing cleavage after } \\
\text { insemination }(\%)\end{array}$} & \multicolumn{3}{|c|}{ No. cleaved oocytes forming blastocysts (\%) } \\
\hline & & $24 \mathrm{~h}$ & $48 \mathrm{~h}$ & Day 5 & Day 6 & Day 7 \\
\hline Control & $121(80.1)^{\mathrm{a}}$ & 79 (52.3) & $116(76.8)^{\mathrm{a}}$ & $20(17.2)$ & $42(36.2)$ & $58(50.0)^{\mathrm{a}}$ \\
\hline FS & $228(68.5)^{\mathrm{ab}}$ & $134(40.2)$ & $222(66.7)^{\mathrm{ab}}$ & $43(19.4)$ & $75(33.8)$ & $117(52.7)^{\mathrm{a}}$ \\
\hline FSF & $263(64.5)^{b}$ & $192(49.3)$ & $251(61.5)^{\mathrm{b}}$ & $46(18.3)$ & $94(37.5)$ & $156(62.2)^{b}$ \\
\hline
\end{tabular}

${ }^{1}$ Monospermic fertilisation.

$*$ Maturation rate $=$ No. oocytes undergoing cleavage at $48 \mathrm{~h}$ p.i. + no. of uncleaved oocytes containing two pro-nuclei at $48 \mathrm{~h}$ p.i.

${ }^{\mathrm{ab}}$ Within column, values with different superscripts differ $(P<0.05)$.

proportion of recipient ewes were pregnant on Day 60 after the transfer of fresh $(23 / 34 ; 68 \%)$ than vitrified embryos $(8 / 27 ; 30 \% ; P<0.01)$. The overall pregnancy loss estimated from Day 20 to Day 60 after transfer did not differ between ewes which received either fresh (4/27; $15 \%)$ or vitrified $(6 / 14 ; 43 \%)$ embryos. There was no effect of ram, sperm type or sex of spermatozoa on pregnancy rate or pregnancy loss after the transfer of fresh or vitrified embryos. However, the number of ewes involved in the transfer of fresh and vitrified embryos was low $(n=34$ and $n=27$ respectively).

Pregnancy rate on Day 60 did not differ between ewes receiving vitrified embryos that were incubated prior to transfer $(4 / 9 ; 44 \%)$ compared with those transferred immediately after re-warming $(4 / 18 ; 22 \%)$.

\section{Lambing and in vivo embryo survival}

Foetal loss between Day 60 of gestation and lambing occurred in two recipient ewes (one from each ET Trial). Of the 34 recipient ewes which received fresh embryos (ET Trial 1), 22 (64.7\%) gave birth to 28 lambs and of the 27 recipient ewes which received vitrified embryos (ET Trial $2)$, seven $(25.9 \%)$ gave birth to eight lambs. The in vivo survival for both fresh and vitrified embryos was similar across all sperm treatments (Table 3). However, a higher proportion of fresh $(41.2 \%)$ compared with vitrified
(14.8\%) embryos survived to lambing $(P<0.01)$. A total of eight neonatal deaths $(8 / 36 ; 22.2 \%)$ were recorded, which were evenly distributed across embryo (fresh vs vitrified) and sperm (Control vs FS vs FSF) treatment groups.

\section{Sex ratio}

Overall, 26/30 lambs (86.7\%) born after transfer of fresh $(20 / 23 ; 87.0 \%)$ and vitrified $(6 / 7 ; 85.7 \%)$ embryos derived from sex-sorted spermatozoa were of the predicted sex. There was a significant difference $(P<0.05)$ in the sex of lambs born from ewes receiving embryos derived from sorted X-spermatozoa (12/12; 100\%) compared with ewes that received embryos derived from non-sorted (Control) spermatozoa (female: $3 / 6 ; 50 \%$ ). Due to low numbers, there was not a significant difference between the sex of lambs born from ewes receiving embryos derived from sorted Y-spermatozoa $(14 / 18 ; 77.8 \%)$ or control spermatozoa (male: $3 / 6 ; 50 \%$ ). The proportion of ewes receiving embryos derived from sex-sorted spermatozoa did not differ from the re-sort analysis values obtained after each sorting session ( $\mathrm{X}$ and $\mathrm{Y}$ data pooled; $89 \pm 1.2 \%$ ).

\section{Gestation length and birth weights}

Lambs were born between Day 149 and Day 157 (ET Trial 1), and between Day 145 and Day 156 (ET Trial 2). There was no effect of sex, sperm type, or number of lambs born

Table 3 Pregnancy rate on Day 20, Day 60 and lambing and in vivo embryo survival of fresh and vitrified embryos, produced after IVF of IVM oocytes with frozen-thawed, non-sorted (Control), frozen-thawed and sorted (FS) and frozen-thawed, sorted, re-frozen and thawed (FSF) spermatozoa, into synchronised recipient ewes.

\begin{tabular}{|c|c|c|c|c|c|c|}
\hline Type of semen & Type of embryo & $\begin{array}{l}\text { No. of } \\
\text { recipient ewes }\end{array}$ & $\begin{array}{c}\text { No. pregnant } \\
\text { on day } 20(\%)^{1}\end{array}$ & $\begin{array}{c}\text { No. pregnant } \\
\text { on day } 60(\%)^{2}\end{array}$ & $\begin{array}{c}\text { No. ewes } \\
\text { lambing }(\%)^{3}\end{array}$ & $\begin{array}{l}\text { Embryo survival } \\
(\%)^{4}\end{array}$ \\
\hline \multirow[t]{2}{*}{ Control } & Fresh & 8 & $6(75)$ & $5(62.5)^{\mathrm{a}}$ & $4(50.0)^{\mathrm{a}}$ & $5 / 16(31.3)^{\mathrm{a}}$ \\
\hline & Vitrified & 6 & $5(83.3)$ & $2(33.3)^{b}$ & $1(16.7)^{b}$ & $1 / 12(8.3)^{\mathrm{b}}$ \\
\hline \multirow[t]{2}{*}{ FS } & Fresh & 9 & $7(77.8)$ & $5(55.6)^{a}$ & $5(55.6)^{a}$ & $6 / 18(33.3)^{\mathrm{a}}$ \\
\hline & Vitrified & 8 & $3(37.5)$ & $2(25.0)^{b}$ & $2(25.0)^{b}$ & $2 / 16(12.5)^{b}$ \\
\hline \multirow[t]{2}{*}{ FSF } & Fresh & 17 & $14(82.4)$ & $13(76.5)^{\mathrm{a}}$ & $13(76.5)^{\mathrm{a}}$ & $17 / 34(50.0)^{\mathrm{a}}$ \\
\hline & Vitrified & 13 & $6(46.2)$ & $4(30.8)^{b}$ & $4(30.8)^{b}$ & $5 / 26(19.2)^{\mathrm{b}}$ \\
\hline
\end{tabular}

\footnotetext{
${ }^{1}$ Determined by peripheral plasma progesterone assay.

${ }^{2}$ Determined by ultrasound.

${ }^{3}$ No. ewes that lambed between Days 149 and 155 (fresh) or Days 145 and 156 (vitrified)/no. recipient ewes $\times 100$.

${ }^{4}$ No. lambs born/no. of transferred embryos $\times 100$.

${ }^{\mathrm{ab}}$ Within columns, values with different superscripts differ $(P<0.05)$.
} 
(single vs twin) on the gestation length. However, the mean gestation length of ewes in ET Trial 2 (150 \pm 1.5 days) was shorter than ewes in ET Trial 1 (152 \pm 0.4 ; $P<0.05)$. Furthermore, the heavier lambs $(>4.0 \mathrm{~kg})$ were born later (after Day 153) in both ET trials. The mean body weight did not differ for lambs born after transfer of either fresh or vitrified embryos (fresh: $5.2 \pm 0.3 \mathrm{~kg}$; vitrified: $4.4 \pm 0.5 \mathrm{~kg})$. However, single lambs were heavier $(5.9 \pm 0.35 \mathrm{~kg})$ and longer in body length $(470 \pm 14.4 \mathrm{~cm})$ than twin-born lambs $(4.2 \pm 0.16 \mathrm{~kg}, 400 \pm 10.3 \mathrm{~cm}$ respectively; $P<0.01$ ) after the transfer of fresh but not vitrified embryos. There was no difference in body weight or length between male or female lambs after the transfer of fresh or vitrified embryos derived from non-sorted (Control) or sex-sorted spermatozoa.

\section{Discussion}

This is the first report of the production of offspring of a pre-determined sex after transfer of embryos produced in vitro with FS and FSF spermatozoa. The results from this study indicate that frozen-thawed ram spermatozoa undergoing sex-sorting and a second cryopreservation step are fully functional when used in IVF.

It was previously demonstrated that, after density gradient preparation, it was possible to sort frozen-thawed ram spermatozoa at high X- and Y-purity and maintain sperm motility, acrosome integrity and migration ability through artificial cervical mucus (Hollinshead et al. 2002 b, 2003). The present study progressed this by investigating in vitro functional capacity of both FS and FSF spermatozoa resulting in production of live offspring.

High resolution of $X$ - and $Y$-sperm populations resulting in $X$ - and Y-purities greater than $89 \%$ was achieved for frozen-thawed spermatozoa. Conversely, Lu et al. (1999) and Cran et al. (1994) reported poor resolution and low purities (X: 82\%; Y: 84\%) after sorting frozen-thawed samples. However, the frozen-thawed samples in the latter studies were not prepared by gradient density centrifugation prior to sorting. Density gradient preparation plays an important role in removing the non-viable (dead) spermatozoa and the majority of the egg yolk and glycerol that is present in cryopreservation diluents. High concentrations of egg yolk can interfere with staining uniformity and contribute to poor resolution, and non-viable spermatozoa can cause interference to the sorting core. This results in a decreased proportion of correctly oriented sperm and lower sorting rates.

Spermatozoa frozen and thawed prior to sorting (FS) had higher motility than non-sorted (Control) spermatozoa after thawing and incubation. Furthermore, the proportion of motile spermatozoa after freezing, thawing, sorting, refreezing, thawing and incubation (FSF) was higher than non-sorted spermatozoa that had undergone two cycles of freeze-thawing (FCF) and incubation. These results are most likely attributable to the selection of only viable spermatozoa during the sorting process. The food dye added to the spermatozoa with the Hoechst stain penetrates the nuclear membrane of non-viable spermatozoa, allowing their identification and exclusion by gating from the sorted sperm population. The additional cryopreservation step after sorting (FSF) may also be a factor in the selection of a more viable sperm population (Maxwell \& Watson 1996).

The FPM of sorted (FS and FSF) spermatozoa was vigorous but lower than non-sorted (Control and FCF) spermatozoa after sorting, thawing and incubation. However, after resuspension of sorted spermatozoa in a more complex medium and $1 \mathrm{~h}$ incubation $\left(37^{\circ} \mathrm{C}\right)$ FPM significantly increased. The distance travelled by the vanguard spermatozoon from FS and FSF treatments in the SMT also suggests that the Tris-based diluent used for both staining and sorting (sheath fluid) spermatozoa is more probably contributing to the decrease in FPM after sorting than the potential physical damage and dilution involved in the sorting process.

Despite the low FPM rating after sorting, higher numbers of FS spermatozoa penetrated $5 \mathrm{~mm}$ into the artificial cervical mucus than for all other treatments (Control, FSF and FCF). However, the distance travelled by the vanguard spermatozoon was similar for all treatments, suggesting that some spermatozoa have a similar ability to migrate to the site of fertilisation. FS spermatozoa had higher motility after sorting than Control, FSF or FCF spermatozoa after thawing, which may have contributed to the greater number of FS spermatozoa migrating through the artificial mucus. The SMT results suggest that successful fertilisation and pregnancy might be achieved after intrauterine or oviductal insemination with FS, FSF or FCF spermatozoa, close to the time of ovulation.

In vitro production of pre-sexed offspring may be a more efficient use of FS and FSF spermatozoa. Fertilisation and cleavage rates were similar for Control and FS spermatozoa. However, FSF spermatozoa were associated with lower fertilisation and cleavage rates compared with Control, possibly indicating more spermatozoa with impaired function. However, this difference in fertilisation rate may also have resulted from incubation of oocytes with higher numbers of non-motile spermatozoa in the FSF treatment creating increased levels of reactive oxygen species (Aitken 1995).

Nevertheless, development of cleaved oocytes to Day 7 blastocysts was higher after insemination with FSF spermatozoa than all for other treatments (FS, Control) and was similar after insemination with FS or Control spermatozoa. Comparable results have been reported after IVF with sorted and non-sorted (control) frozen-thawed bull spermatozoa (Lu et al. 2001, Zhang et al. 2004) but blastocyst rates as high as those achieved in the present study have not been reported. The increased selection pressure on spermatozoa with intact membranes after freeze-thawing, sorting and a second re-cryopreservation may be associated with the isolation of a population of spermatozoa yielding a higher development rate to blastocysts after IVF than Control or FS spermatozoa. ET trials incorporating 
higher numbers of recipients are required, since although statistically non-significant the pregnancy rate determined by ultrasound on Day 60 (82\%) was higher after transfer of embryos derived from FSF spermatozoa compared with FS (56\%) and Control (62\%) spermatozoa. Pregnancy loss between Day 20 and Day 60, and between Day 60 and lambing did not differ between ewes receiving Control, FS or FSF derived embryos (Table 3). These results and previous reports (reviewed by Seidel \& Garner 2002) suggest that the staining, sorting, cryopreservation and re-cryopreservation processes for FS and FSF spermatozoa do not appear to cause DNA damage that influences embryonic survival.

The majority of blastocysts in the present study developed on Day 6 of culture regardless of the type of spermatozoa used (FS, FSF or Control). This is in contrast to previous reports of delayed embryonic development after IVF with spermatozoa sorted on either a high speed (Lu et al. 1999) or a standard speed flow cytometer (Cran et al. 1993, 1994, Merton et al. 1997) prior to freeze-thawing compared with non-sorted, frozen-thawed or fresh bull spermatozoa. Significant improvements in both biological (bull: Schenk et al. 1999, ram: F K Hollinshead, unpublished observations) and instrumental (Rens et al. 1999, Campos-Chillon \& De La Torre 2003, Suh \& Schenk 2003) aspects of flow cytometric sperm sorting have occurred since these reports. Such developments have significantly reduced the dilution rate of spermatozoa during staining (Maxwell \& Johnson 1999) and may be contributing to improvements in the IVF parameters found in this study compared with earlier reports.

Transfer of fresh and frozen-thawed (conventional slow freezing) embryos derived from sorted frozen-thawed bull spermatozoa (Cran et al. 1994) resulted in pregnancy rates similar to those observed after the transfer of fresh and vitrified embryos derived from FS and FSF spermatozoa in the present study (Table 3). Vitrification instead of conventional slow freezing was utilised as it is a quick, simple and cost-effective method of cyropreserving embryos (Vajta 2000) making it commercially attractive, especially in combination with in vitro production of 'pre-sexed' embryos. The overall pregnancy rates after the transfer of in vitro produced fresh and vitrified embryos in this study were comparable with those reported by other workers after transfer of fresh and vitrified embryos derived from non-sorted ram spermatozoa (fresh: 41-66\%, Martinez et al. 1997, O'Brien et al. 1997, Brown \& Radeziewic 1998, Dattena et al. 2000, Walmsley et al. 2000, Peura et al. 2002, vitrified: 33-50\%, Dattena et al. 2000, Walmsley et al. 1999, Fogarty et al. 2000, Peura et al. 2002). In the present study, the pregnancy rate and in vivo embryo survival was higher after the transfer of fresh than vitrified embryos (Table 3). Vitrification eliminates the adverse effects of ice crystal formation and chilling injury during freezing (Vajta 2000), but the embryonic cells still undergo membrane damage and osmotic stress due to dehydration and toxicity from the high concentrations of cryoprotectants used. These factors most probably contributed to the lower pregnancy and lambing rate after transfer of vitrified embryos.

Embryos vitrified after 6 days of culture were incubated for $18 \mathrm{~h}$ prior to transfer for two purposes. First, so that they would be at the same developmental stage as the embryos vitrified after 7 days and thawed just prior to transfer into recipient ewes. Secondly, the incubation enabled assessment of re-expansion after re-warming as a measure of viability (Naitana et al. 1995, Donnay et al. 1998, Dattena et al. 2000). All of the Day 6 vitrified embryos re-expanded after thawing. This re-expansion rate is higher than previously reported for in vitro produced embryos, but is similar to in vivo derived, vitrified ovine embryos (Dattena et al. 2000). As observed in humans (Guerif et al. 2003), the pregnancy rate was similar for embryos transferred into ewes within a few hours of thawing and embryos that were thawed and cultured overnight prior to transfer.

Incidence of lambs with large birth weights (range: $2.5-9.5 \mathrm{~kg}$ ) was higher than that reported for naturally bred Merino lambs (4 kg; Brown \& Radziewic 1998) and the lambs born from the same flock of ewes after Al with non-sorted (control) or sorted frozen-thawed spermatozoa (range: 3.1-5.4 kg; Hollinshead et al., 2002a). Similar findings after the transfer of in vitro produced embryos have been reported previously for sheep (Walker et al. 1992, 1996, Thompson et al. 1995, Holm et al. 1996, Brown \& Radziewic 1998). A number of factors have been implicated in the birth of large offspring after ET of in vitro produced embryos (reviewed by Walker et al. 1992, 1996,) including asynchronous ET (Wilmut \& Sales 1981), particularly after the transfer of vitrified embryos (Naitana et al., 1995, Leoni et al. 2003), progesterone treatment of ewes early in gestation (Kleeman et al. 1994) and the use of serum as the source of protein during in vitro culture (Thompson et al. 1995). Despite substituting serum with HSA in the in vitro culture media, the procedures of in vitro production of embryos and possibly progesterone supplementation at Day 12 of gestation may have had a mitogenic effect on embryonic cells or altered the distribution of cells in the trophectoderm and inner cell mass (Brown \& Radziewic 1998), ultimately resulting in enhanced foetal growth and increased birth weights of a proportion of the lambs in this study.

At present, approximately $30 \%$ of fresh and fewer than $10 \%$ of frozen-thawed spermatozoa prepared for sorting can be effectively sex-sorted. This inefficiency is due to both biological and mechanical losses that occur during the sorting processes (reviewed by Seidel \& Garner 2002). Lower numbers of frozen-thawed spermatozoa are sorted because of the increased proportion of spermatozoa with damaged membranes after thawing. Efficiency may be improved by further optimisation of flow cytometer parameters, sperm preparation and cryopreservation methods. Furthermore, future research into improved methods for preparation of FS and FSF spermatozoa for IVF may help 
to increase fertilisation and cleavage rates and ultimately the efficiency with which pre-sexed embryos can be produced.

In conclusion, this study has demonstrated that frozenthawed samples can be sex-sorted at high purities and then re-cryopreserved and successfully used in an IVF system to produce viable embryos. Assisted reproductive techniques (sperm and embryo preservation, IVF, ET) were successfully combined with sperm-sexing technology, resulting in the production of offspring. This significant development will help overcome limitations imposed by distance of the sperm sorter from the site of semen collection and ET in both livestock and wildlife species.

\section{Acknowledgements}

This work was supported by the Australian Research Council; $\mathrm{XY}$, Inc. (Fort Collins, CO, USA); and the Zoological Parks Board of NSW. The authors thank Mr S Burgun and Mr B Biffin for their on-farm assistance, Mr R Wadley and Ms M Meyers for operating the MoFlo SX cell sorter, Ms K Heasman and Dr F Scherch for their technical assistance and Dr L Gillan for assistance with the manuscript.

\section{References}

Abeydeera LR, Johnson LA, Welch GR, Wang WH, Boquest AC, Cantley TC, Rieke A \& Day BN 1998 Birth of piglets preselected for gender following in vitro fertilisation of in vitro matured pig oocytes by $\mathrm{X}$ and $\mathrm{Y}$ chromosome bearing spermatozoa sorted by high speed flow cytometry. Theriogenology 50 981-988.

Aitken RJ 1995 Free radicals, lipid peroxidation and sperm function. Reproduction, Fertility, and Development 7 659-668.

Brown BW \& Radziewic T 1998 Production of sheep embryos in vitro and development of progeny following single and twin embryo transfers. Theriogenology 49 1525-1536.

Campos-Chillon LF \& De La Torre JF 2003 Effect of concentration of sexed bovine sperm sorted at 40 and 50 psi on developmental capacity of in vitro produced embryos. Theriogenology $\mathbf{5 9} 506$.

Catt SL, Catt JW, Gomez MC, Maxwell WMC \& Evans G 1996 Birth of a male lamb derived from an in vitro matured oocyte fertilised by intracytoplasmic injection of a single presumptive male sperm. Veterinary Record 139 494-495.

Cran DG, Johnson LA, Miller NGA, Cochrane D \& Polge G 1993 Production of bovine calves following separation of $\mathrm{X}$ - and $\mathrm{Y}$ chromosome bearing sperm and in vitro fertilisation. Veterinary Record 132 40-41.

Cran DG, Cochrane DJ \& Johnson LA 1994 Separation of X- and Ychromosome bearing bovine sperm by flow cytometry for use in IVF. Theriogenology 41183.

Cran DG, Johnson LA \& Polge C 1995 Sex pre-selection in cattle: a field trial. Veterinary Record 136 495-496.

Dattena M, Ptak G, Loi P \& Cappai P 2000 Survival and viability of vitrified in vitro and in vivo produced ovine blastocysts. Theriogenology 53 1511-1519.

Donnay I, Auquier P, Kaidi S, Carolan C, Lonergan P, Mermillod P \& Massip A 1998 Vitrification of in vitro produced bovine blastocysts: methodological studies and developmental capacity. Animal Reproduction Science 52 93-104.

Evans G \& Maxwell WMC 1987 Salamon's Artificial Insemination of Sheep and Goats. Sydney: Butterworths.

Fogarty NM, Maxwell WMC, Eppleston J \& Evans G 2000 The viability of transferred sheep embryos after long-term cryopreservation. Reproduction, Fertility, and Development 12 31-37.
Fry RC, Earl CR, Hollinshead FK, Wild D \& Lindemans W 2004 Pregnancies from frozen IVF cattle embryos using sex-sorted and unsorted sperm. Reproduction, Fertility, and Development 16254.

Fugger EF 1999 Clinical experience with flow cytometric separation of human X-and Y-chromosome bearing sperm. Theriogenology $\mathbf{5 2}$ $1435-1440$.

Fugger EF, Black SH, Keyvanfar K \& Schulman JD 1998 Births of normal daughters after microSort sperm separation and intrauterine insemination, in-vitro fertilisation, or intracytoplasmic sperm injection. Human Reproduction 13 2367-2370.

Gardner DK \& Schoolcraft WB 1999 In vitro culture of human blastocysts. In Towards Reproductive Certainty: Fertility and Genetics Beyond 1999, pp 378-388. Eds R Jansen \& D Mortimer. Carnforth: Parthenon Press.

Guerif F, Cadoret V, Poindron J, Lansac J \& Royere D 2003 Overnight incubation improves selection of frozen-thawed blastocysts for transfer: preliminary study using supernumerary embryos. Theriogenology 60 1457-1466.

Hollinshead FK, O'Brien JK, Maxwell WMC \& Evans G 2002a Production of lambs of predetermined sex after the insemination of ewes with low numbers of frozen-thawed sorted X- or Y- chromosome bearing spermatozoa. Reproduction, Fertility, and Development 11 123-126.

Hollinshead FK, Maxwell WMC, Evans G \& O'Brien JK 2002b Flow cytometric sorting of frozen-thawed ram spermatozoa. Reproduction, Fertility, and Development $\mathbf{1 4} 21$.

Hollinshead FK, Evans G, Maxwell WMC \& O'Brien JK 2003 Sexsorting and re-cryopreservation of frozen-thawed ram sperm for in vitro embryo production. Theriogenology 59209.

Holm P, Walker SK \& Seamark RF 1996 Embryo viability, duration of gestation and birth weight in sheep after transfer of in vitro matured and in vitro fertilised zygotes cultured in vitro or in vivo. Journal of Reproduction and Fertility 107 175-181.

Howard JG, Bush M \& Wilt DE 1986 Semen collection, analysis and cryopreservation in non-domestic mammals. In Current Therapy in Theriogenology, pp 1047-1053. Ed. DA Morrow. Philadelphia, PA: WB Saunders Co.

Johnson LA \& Pinkel D 1986 Modification of a laser-based flow cytometer for high resolution DNA analysis of mammalian spermatozoa. Cytometry 7 268-273.

Johnson LA \& Welch GR 1999 Sex pre-selection: high-speed flow cytometric sorting of $X$ and $Y$ sperm for maximum efficiency. Theriogenology 52 1323-1341.

Johnson LA, Flook JP \& Hawk HW 1989 Sex pre-selection in rabbits: live births from X- and Y-sperm separated by DNA and cell sorting. Biology of Reproduction 41 199-203.

Johnson LA, Guthrie HD, Fiser P, Maxwell WMC, Welch GR \& Garrett WM 2000 Cryopreservation of flow cytometrically sorted boar sperm: effects on in vivo embryo development. Journal of Animal Science 78 (Suppl 1) 198.

Kleeman DO, Walker SK \& Seamark RF 1994 Enhanced foetal growth in sheep administered progesterone during the first three days of pregnancy. Journal of Reproduction and Fertility 102 411-417.

Leoni G, Berlinguer F, Rosati I, Bogliolo L, Ledda S \& Naitana S 2003 Resumption of metabolic activity of vitrified/warmed ovine embryos. Molecular Reproduction and Development 64 207-213.

Levinson G, Keyvanfar K, Wu JC, Fugger EF, Fields RA, Harton GL, Palmer FT, Sisson ME, Starr KM, Dennison-Lagos L, Calvo L, Sherins RJ, Bick D, Schulman JD \& Black SH 1995 DNA-based $\mathrm{X}$-enriched sperm separation as an adjunct to preimplantation genetic testing for the prevention of X-linked disease. Human Reproduction 10 979-982.

Lindsey AC, Schenk JL, Graham JK, Bruemmer JE \& Squires EL 2002 Hysteroscopic insemination of low numbers of flow sorted fresh and frozen thawed stallion spermatozoa. Equine Veterinary Journal $34121-127$. 
Lu KH, Cran DG \& Seidel GE Jr 1999 In vitro fertilisation with flowcytometrically-sorted bovine sperm. Theriogenology $\mathbf{5 2}$ 1393-1405.

Lu KH, Suh TK \& Seidel GE Jr 2001 In vitro fertilisation of bovine oocytes with flow-cytometrically sorted and unsorted sperm from different bulls. Theriogenology 55431.

Martinez AG, Furnus CC, Matkovic M \& De Matos DG 1997 Lambing from transfer of in vivo and in vitro produced fresh or vitrified embryos. Theriogenology 47351.

Maxwell WMC \& Watson PF 1996 Recent progress in the preservation of ram semen. Animal Reproduction Science 42 55-65.

Maxwell WMC \& Johnson LA 1999 Physiology of spermatozoa at high dilution rates: the influence of seminal plasma. Theriogenology 52 1353-1362.

Merton JS, Haring RM, Stap J, Hoebe RA \& Aten JA 1997 Effect of flow cytometrically sorted frozen/thawed semen on success rate of in vitro bovine embryo production. Theriogenology 47295.

Molinia FC, Evans G \& Maxwell WMC 1996 Fertility of ram spermatozoa pellet-frozen in zwitterion buffered diluents. Reproduction, Nutrition, Development 36 21-29.

Mortimer D, Mortimer ST, Shu MA \& Swart R 1990 A simplified approach to sperm-cervical mucus interaction testing using a hyaluronate migration test. Human Reproduction 5 835-841.

Naitana S, Dattena M, Gallus M, Loi P, Branca A, Ledda S \& Cappai P 1995 Recipient synchronization affects viability of vitrified ovine blastocysts. Theriogenology 43 1371-1378.

O'Brien JK, Catt SL, Ireland KA, Maxwell WMC \& Evans G 1996 In vitro and in vivo developmental capacity of oocytes from prepubertal and adult sheep. Theriogenology 47 1433-1443.

O'Brien JK, Beck NFG, Maxwell WMC \& Evans G 1997 Effect of hormone pre-treatment of prepubertal sheep on the production and developmental capacity of oocytes in vitro and in vivo. Reproduction, Fertility, and Development 9 625-631.

O'Brien JK, Hollinshead FK, Evans KM, Evans G \& Maxwell WMC 2003 Flow cyometric sorting of frozen-thawed spermatozoa: application to livestock and wildlife species. Reproduction, Fertility, and Development 15 351-359.

Pearce DT, Gray SJ, Oldham CM \& Wilson HR 1984 The use of intravaginal sponges and PMSG. Proceedings of the Australian Society of Animal Production 15 164-170.

Peura TT, Hartwich KM, Kelly JM, Hamilton HM, Kleeman DO, Rudiger SR \& Walker SK 2002 Survival of fresh and vitrified sheep IVP and cloned embryos after embryo transfer. Reproduction, Fertility, and Development 1416.

Ptak G, Clinton M, Tischner M, Barboni B, Mattioli M \& Loi P 2002 Improving delivery and offspring viability of in vitro-produced and cloned sheep embryos. Biology of Reproduction 67 1719-1725.

Rath D, Johnson LA, Dobrinsky JR, Welch GR \& Niemann H 1997 Production of piglets pre-selected for sex following in vitro fertilisation with $\mathrm{X}$ and $\mathrm{Y}$ chromosome bearing spermatozoa sorted by flow cytometry. Theriogenology 47 795-800.

Rath D, Long CR, Dobrinsky JR, Welch GR, Schreier LL \& Johnson LA 1999 In vitro production of sexed embryos for gender preselection: high-speed sorting of X-chromosome-bearing sperm to produce pigs after embryo transfer. Journal of Animal Science $\mathbf{7 7}$ 3346-3352.

Rens W, Welch GR \& Johnson LA 1998 A novel nozzle for more efficient sperm orientation to improve sperm sorting efficiency of $X$ and $\mathrm{Y}$ chromosome bearing sperm. Cytometry 33 476-481.

Rens W, Welch GR \& Johnson LA 1999 Improved flow cytometric sorting of $\mathrm{X}$ - and $\mathrm{Y}$ - chromosome bearing sperm: substantial increase in yield of sexed semen. Molecular Reproduction and Development 52 50-56.

Robertson HA \& Sarda IR 1971 A very early pregnancy test for mammals: its application to the cow, ewe and sow. Journal of Endocrinology 49 407-419.
Roth TL, Weiss RB, Buff JL, Bush LM, Wilt DE \& Bush M 1988 Heterologous in vitro fertilisation and sperm capacitation in an endangered African antelope, the scimitar-horned oryx (Oyx dammah). Biology of Reproduction 58 475-482.

Scaramuzzi RJ, Downing JA, Campbell BK \& Cognie Y 1988 Control of fertility and fecundity of sheep by means of hormonal manipulation. Australian Journal of Biological Sciences 41 37-45.

Schenk JL \& DeGrofft DL 2003 Insemination of cow elk with sexed frozen semen. Theriogenology 59514.

Schenk JL, Suh TK, Cran DG \& Seidel GE Jr 1999 Cryopreservation of flow-sorted bovine spermatozoa. Theriogenology $\mathbf{5 2}$ 1357-1391.

Seidel GE Jr \& Garner DL 2002 Current status of sexing mammalian spermatozoa. Reproduction 124 733-743.

Seidel GE Jr, Schenk JL, Herickhoff LA, Doyle SP, Brink Z, Green RD \& Cran DG 1999 Insemination of heifers with sexed sperm. Theriogenology 52 1407-1420.

Stap J, Hoebe RA, Merton JS, Haring RM, Bakker PJM \& Aten JA 1998 Improving the resolution of cryopreserved X- and Y- sperm during DNA flow cytometric analysis with the addition of percoll to quench the fluorescence of dead sperm. Journal of Animal Science 76 1896-1902.

Suh TK \& Schenk JL 2003 Pressure during flow sorting of bull sperm affects post-thaw motility characteristics. Theriogenology 59516.

Tervit HR \& Rowson EA 1972 Birth of lambs after culture of sheep ova in vitro for up to 6 days. Journal of Reproduction and Fertility 38 177-179.

Thompson JG, Gardner DK, Pugh PA, McMillan WH \& Tervit HR 1995 Lamb birth weight is affected by culture system utilized during in vitro pre-elongation development of ovine embryos. Biology of Reproduction 53 1385-1391.

Vajta G 2000 Vitrification of the oocytes and embryos of domestic animals. Animal Reproduction Science 60-61 357-364.

Vajta G, Kuwayanna M, Holm P, Booth PJ, Jacobsen H, Greve T \& Callesen H 1998 A new way to avoid cryoinjuries of mammalian ova and embryos: the OPS vitrification. Molecular Reproduction and Development $\mathbf{5 1} 53-58$.

Walker SK, Heard TM \& Seamark RF 1992 In vitro culture of sheep embryos without co-culture: successes and perspectives. Theriogenology 37 111-126.

Walker SK, Hartwich KM \& Seamark RF 1996 The production of unusually large offspring following embryo manipulation: concepts and challenges. Theriogenology 45 111-120.

Walmsley SE, Pollard JW, Randall AE \& Morris LHA 1999 Survival of in vitro produced ovine embryos of different developmental stages after vitrification in EFS-40. Theriogenology 51177.

Walmsley SE, Pollard JW, Buschbeck C, Rumph N \& Buckrell BC 2000 Pregnancy rates for IVP ovine embryos transferred on day 2 versus day 6. Reproduction in Small Ruminants, ICAR satellite meeting, Sandnes, Norway. p 69.

Welch GR \& Johnson LA 1999 Sex pre-selection: laboratory validation of the sperm sex ratio of flow sorted X- and Y-sperm by sort reanalysis for DNA. Theriogenology 52 1343-1352.

Wilmut I \& Sales DI 1981 Effect of asynchronous environment on embryonic development in the sheep. Journal of Reproduction and Fertility 61 179-184.

Zhang M, Lu KH \& Seidel GE Jr 2004 Development of bovine embryos after in vitro fertilisation of oocytes with flow cytometrically sorted, stained and unsorted sperm from different bulls. Theriogenology 60 1657-1663.

Received 19 October 2003

First decision 28 January 2004

Accepted 24 February 2004 